\title{
O uso da modelagem representacional do sistema digestório e respiratório no ensino de ciências como ferramenta pedagógica: perspectiva para uma aprendizagem significativa no ensino fundamental
}

The use of representational modeling and respiratory digestive system in science education as a pedagogycal tool: prospects for a meaningful learning in elementary school

\author{
P. W. P. Gomes ${ }^{1}$; J. S. Modesto ${ }^{1}$; P. W. P. Gomes ${ }^{2}$; R. F. Souza ${ }^{3}$; A. S. Martins- \\ $\mathrm{Jr}^{4}$ \\ ${ }^{I}$ Graduandos de Ciências Naturais - Biologia, Universidade do Estado do Pará, 68860-000, Salvaterra-PA, Brasil. \\ ${ }^{2}$ Programa de Pós Praduação em Química, Universidade Federal do Pará, Universidade Federal do Pará, 66075 - \\ 970 Belém-PA, Brasil. \\ ${ }^{3}$ Departamento de Ciências Naturais/Campus XIX-Salvaterra, Universidade do Estado do Pará, 68860-000, \\ Salvaterra-PA, Brasil \\ ${ }^{4}$ Programa de Pós Graduação em Botânica do Instituto de Pesquisa Jardim Botânico do Rio de Janeiro/ Escola \\ Nacional de Botânica tropical. Universidade do Estado do Pará, 66652-000, Belém-PA, Brasil \\ *weslemuepa@hotmail.com
}

(Recebido em 08 de abril de 2016; aceito em 26 de abril de 2016)

\begin{abstract}
A modelagem como ferramenta didática tem por finalidade proporcionar a aprendizagem significativa e prazerosa. Assim, este trabalho objetivou o ensino do sistema digestório e respiratório por meio da modelagem representacional no intuito de colaborar com a aprendizagem dos discentes. O trabalho foi realizado no dia 8 de abril de 2015 , com a turma de $8^{\circ}$ ano, em uma escola pública municipal de Salvaterra, arquipélago do Marajó, Pará. No primeiro momento, foi aplicado um questionário acerca do conhecimento da turma sobre modelagem, na qual $94 \%$ disseram não ter conhecimento. Com isso, foi feita breve introdução do assunto a ser abordado, logo após a turma foi dividida em duas equipes (A e B), em que fizeram a montagem dos modelos a partir das peças (cada peça representando um órgão) que lhe foram repassadas. Além disso, foi feita dinâmica de perguntas diretas sobre o assunto aos grupos, onde a equipe. A ganhou com maior número de acertos. As questões foram discutidas com o intento de não haver dúvidas. Ao final, foram aplicados dois questionários, um sobre a importância da modelagem na disciplina de ciências e outro sobre um conceito avaliativo do trabalho, $96 \%$ e $60 \%$ foi de resultados positivos, respectivamente. A maioria dos discentes conseguiram compreender as informações oferecidas por meio do recurso pedagógico aplicado, pois as equipes não tiveram dificuldades para montar os modelos, o que quebra os paradigmas de sala de aula e enaltece o uso da modelagem representacional no ensino de ciências para uma aprendizagem significativa.

Palavras-chave: Aprendizagem significativa, Ensino de ciências, Modelagem representacional
\end{abstract}

The modeling as a didactic tool aims to provide meaningful and enjoyable learning. Thus, this work aimed to the digestive system and respiratory education through representational modeling in order to collaborate with the learning of students. The work was carried out in day 8 of April 2015, with the class of eighth-graders in public school Council of Salvaterra, Marajó archipelago, para. At first, it was applied a questionnaire about knowledge of class about modeling, in which $94 \%$ said not having knowledge. With this brief introduction has been made of the subject to be discussed right after the class was divided into two teams (A and B), which made the Assembly of models from parts (each piece represents an organ) which were passed on. In addition, dynamic was made direct questions on the subject to the groups, where the team won with the highest number of hits. The issues were discussed with the intent to be no doubts. In the end, two questionnaires were applied, one on the importance of modeling in the discipline of science and another on an evaluative concept work, $96 \%$ and $60 \%$ of positive results, respectively. Most students were able to understand the information offered through the pedagogical resource applied because the teams did not have difficulties to assemble the models, which breaks the paradigms of classroom and extols the use of representational modeling in science education to a significant learning. Keywords: Meaningful learning, Teaching science, Representational modeling 


\section{INTRODUÇÃO}

A construção de modelos no ensino torna a aprendizagem mais participativa, pois a atividade de construir modelos permite ao aluno a integração de conhecimentos abstratos [1]. Os modelos contribuem para a construção de novos conhecimentos, a partir do conhecimento prévio que o aluno possui. Barab et al. [2] reforça que o aprendizado participativo atua como âncora na construção de significados, conceitos e representações. Segundo Greca; Santos [3] a modelização é uma das táticas mais efetivas para a melhor compreensão dos conceitos científicos. Os modelos podem ser classificados em três categorias, modelo representacional, modelo teórico e modelo imaginário. $\mathrm{O}$ modelo representacional é definido como forma tridimensional de qualquer outro sistema; o modelo teórico é ligado por um conjunto de pressupostos sobre um objeto ou sistema, em que impõe a estes uma estrutura ou mecanismo interno; o modelo imaginário é determinado por um conjunto de hipóteses descritas para descrever como seria um objeto ou sistema, com objetivo de melhorar a compreensão dos pressupostos que o constituem [4].

O modelo é a essência das teorias pedagógicas para melhor representação do que se quer ensinar, o modelo representacional apresentou-se na forma de maquete, sendo uma representação física tridimensional $[5,6]$. O uso de modelos para o ensino de ciências é de fundamental importância, pois ao se construir um modelo representacional exercita-se a capacidade de pensar e criativa com objetivos que transformam o próprio universo escolar. Não apenas construir modelos, mas modelos que incrementem nossas formas de construir a realidade, acrescentando uma mudança de qualidade ao conhecimento científico escolar [7]. No entanto, o estudante deve entender que os modelos são representações parciais da realidade, e que na modelagem existe as suas simplificações e limitações que devem ser entendidas independentemente das implicações teóricas [1].

Isso evidência a necessidade de romper com o sistema de ensino tradicional, baseado na memorização de conteúdos superficiais e inertes, e passar a um sistema em que o professor atue como orientador na construção do conhecimento e em que o aluno participe ativamente do seu aprendizado, construindo relações significativas com o conhecimento através de suas experiências [1].

Segundo Moreira [8] a aprendizagem é dita significativa quando uma nova informação, conceito ou posição, juntamente com conhecimentos preexistentes, se interagem abrindo espaços a novos conceitos. A partir deste momento, atribuem-se novos significados e se diferenciam progressivamente. À medida que o aprendiz faz assimilações de modo significante passa a ser mais completo em nível e conhecimento onde, posteriormente, servirá de âncora para a atribuição de novos significados. Essa organização intencional, planejada e sistemática das finalidades são condições da aprendizagem escolar específica de ensino. Sendo assim, um processo de aprender e assimilar conhecimentos que se manifestam na vida interna e externa do sujeito com relação ao seu ambiente.

Para Mendonça et al. [9], é preciso que os próprios professores trabalhem em conjunto na elaboração de um planejamento interdisciplinar contextualizado e com objetivos cognitivos comuns, que busquem suprir a carência do ensino de qualidade. Ainda hoje, a utilização de novas práticas no ensino de ciências, é abordada por muitos professores como barreira para se ter uma evolução da aprendizagem no ensino, pois ações deste tipo requer tempo e uma preparação adequada. No entanto, quando ocorrem mudanças significativas elas se tornam visíveis no momento que se utiliza de uma aula dinâmica com maior participação dos alunos, estimulando os sentidos e fazendo com que se torne real aquilo que só pode ser visualizado por figuras em livros didáticos. Souza et at. [10] discute o fato de modelos como ferramenta pedagógica, na qual tem a possibilidade de trabalhar a interatividade e raciocínio dos estudantes exercitando a mente com uma maneira lúdica de assimilar novos saberes. Em análise as propostas curriculares das unidades federadas, é dedicado em média apenas um período $12 \%$ a $15 \%$ para o ensino de ciências. Com isto, são ministrados conteúdos que não levam em conta 
atividades importantes para a construção de conhecimento, como a dinamização de conteúdo e temas sem bases que possam amarrar os novos conhecimentos em processo de assimilação [11].

O professor precisa conhecer a realidade de seus alunos, e levar para a sala de aula propostas de ensino que sejam prazerosas de forma que se compreenda o sentido da aprendizagem. Mesmo que, hajam entraves que ainda perpetuam na educação, como a carência de recursos, pouco tempo disponível para ensinar ciência, professores que não tenham o conhecimento para desenvolver uma aula pratica, a partir de experimentações, lúdicos e com o uso de modelos. Diante do exposto, este trabalho teve como objetivo colaborar com a aprendizagem dos alunos do oitavo ano ( $7^{\mathrm{a}}$ série) do ensino fundamental, abordando o sistema digestório e respiratório a partir do uso da modelagem representacional como recurso pedagógico no intento de elucidar o funcionamento dos sistemas, seus componentes e suas características.

\section{MATERIAL E MÉTODOS}

\section{1. Área de estudo}

O trabalho foi desenvolvido com uma turma de $8^{\circ}$ ano do ensino fundamental (antiga $7^{\mathrm{a}}$ série) no dia 8 de abril de 2015 na escola municipal de ensino fundamental, localizada no município de Salvaterra, Arquipélago do Marajó, Pará. No primeiro momento (antes do início da aula), foi feito um levantamento qualitativo em relação aos conhecimentos prévios dos alunos sobre o assunto em questão. Em seguida foi aplicado um questionário contendo questões sobre o uso da modelagem no ensino de ciências. $\mathrm{O}$ segundo momento da aula procedeu-se uma breve conversa com os alunos, partindo dessa conversa deu se a introdução ao sistema digestório e respiratório, juntamente com os subsunçores dos alunos associados ao assunto abordado em sala pelos ministrantes, os discentes foram orientados a montar um modelo do sistema digestório, em seguida do sistema respiratório até se chegar a modelagem completa, pois os dois modelos encontravam-se desencaixados, no entanto, havia um terceiro modelo do sistema respiratório previamente montando. Obteve-se como avaliação de uma aprendizagem significativa a montagem correta das peças constituintes da modelagem representacional.

\subsection{Modelagem do sistema Digestório e Respiratório}

A turma formada por 30 alunos foi dividida em duas equipes de 15 alunos cada, denominadas equipe A e B com objetivo de maximizar a participação dos mesmos no trabalho. Posteriormente, foram entregues aos discentes, peças referentes aos órgãos de cada sistema, para que eles a identificassem e montassem. Foi estipulado um tempo de $5 \mathrm{~min}$, para que as duas equipes montassem o modelo do sistema digestório e ao término foram comparados com a ilustração correta do sistema supracitado, projetada pelo Datashow. Ao final desta primeira atividade, cada equipe comentou o nome e a função de cada órgão que representava o sistema digestório.

A segunda atividade foi a montagem do sistema respiratório, que utilizou a mesma dinâmica da atividade anterior. No entanto, também foi usado o modelo tridimensional do sistema respiratório, já montado pelos executores do trabalho, onde os alunos observaram qual a função de cada órgão. Para finalizar o trabalho, houve uma dinâmica entre as duas equipes, na qual foram feitas perguntas sobre o sistema digestório e respiratório, tendo como objetivo verificar a aprendizagem alcançada no decorrer da atividade. Por fim, houve a aplicação de dois questionários, um em relação a importância da modelagem no ensino de ciências e outro em que os alunos deram conceitos para o trabalho, os quais iam de ruim a excelente.

\section{RESULTADOS E DISCUSSÃO}

Foi aplicado um questionário com perguntas diretas antes de iniciar as atividades, tendo por objetivo analisar o conhecimento prévio da turma sobre o conceito de modelagem e em seguida adentrar no assunto da modelagem aplicada aos sistemas digestório e respiratório. O resultado foi discrepante quando se fala da modelagem nas aulas de ciências, visto que a maioria dos 
alunos não tinham conhecimento da mesma (Figura 1). Estes resultados aproximam-se dos estudos realizados por Treagust; Chittleborough [12], em que os estudantes tem dificuldade de entender o conceito de modelo, pois não apresentam uma concepção desenvolvida sobre modelagem, a não ser que algum professor tenha trabalhado isso com eles. $\mathrm{O}$ ensino de Ciências nas escolas de ensino fundamental é baseado na simples transmissão de conteúdo, tendo como recurso base o livro didático e a lousa; no entanto, muitas outras escolas já mudaram com os avanços produzidos nas últimas décadas, especialmente no ensino de Ciências [13].

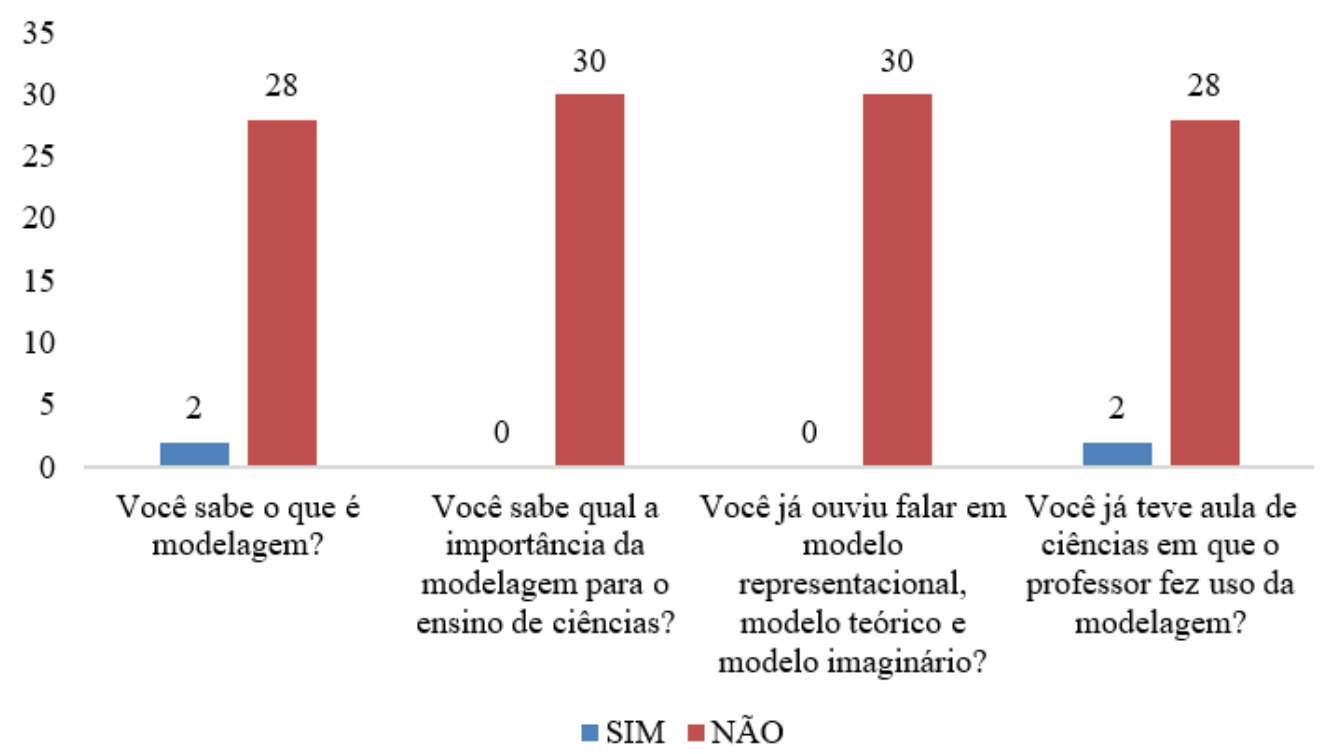

Figura 1: Questionário aplicado antes da execução do trabalho, o qual visava avaliar o conhecimento prévio da turma no contexto do uso de modelos e a modelagem no ensino de ciências.

Foi dado ênfase na contextualização do assunto estudado, onde os próprios alunos fizeram alguns questionamentos sobre a sua alimentação, problemas como asma, má digestão e outros assuntos afins. Visto que a contextualização serve como base primordial para que haja uma educação de qualidade, servindo para somar com o cognitivo do aprendiz [14]. Ao término desta breve introdução, foram repassados para aos alunos os modelos confeccionados pelos autores do artigo, sendo que cada sistema se encontrava fragmentado, pois cada peça representava um órgão, neste momento a turma foi dividida em dois grupos, A e B e deu-se início para a primeira dinâmica da aula.

As duas equipes montaram os modelos de cada sistema e após a montagem dos mesmos, os autores deste artigo compararam a modelagem do sistema digestório e respiratório com as imagens que estavam sendo projetadas em slide. Com isso, deu-se início há discussão na sala em relação a função de cada órgão e como eles funcionam em um sistema. As dúvidas dos alunos foram surgindo e a interação com o assunto tornou-se maior. Foi observado através da dinâmica entre as equipes A e B, que as perguntas (Tabela 1), foram na sua maioria respondidas corretamente, demostrando que o grau de entendimento dos alunos foi significativo em relação ao assunto abordado neste trabalho. 
Tabela 1: Perguntas feitas na dinâmica das equipes A e B.

\begin{tabular}{cccc}
\hline & \multicolumn{2}{l}{ Equipes } & Gabarito \\
\cline { 2 - 4 } Perguntas & A & B & (V ou F) \\
\hline
\end{tabular}

Os pulmões encontram-se protegidos pela caixa torácica?

V V V

A prática de exercícios físicos como correr e andar de bicicleta é de fundamental importância para o bom funcionamento do sistema respiratório?

V V V

As vias respiratórias são constituídas apenas por fossas nasais, faringe, laringe e alvéolos pulmonares?

F $\quad F$

F

As vias respiratórias são conjuntos de órgãos que captam $\mathrm{o}$ ar do exterior e o fazem chegar aos pulmões?

V V V

Hematose pulmonar é a troca gasosa que se dá nos alvéolos pulmonares e que permite a oxigenação do $\begin{array}{lllll}\mathrm{F} & \mathbf{V}\end{array}$ sangue?

O processo digestório passa por todos os seguintes órgãos: boca, esôfago, estômago, fígado, vesícula biliar, pâncreas, $\mathrm{V} \quad \mathrm{V} \quad \mathrm{V}$ intestino delgado, intestino grosso e ânus?

A absorção de água e nutrientes ocorre no intestino $F \quad F \quad$ F delgado?

A digestão é um processo unicamente mecânico?

F $\quad F$

$\mathbf{F}$

Os dentes da nossa boca são importantes para mastigação e digestão?

V V V V

O esôfago é um canal por onde o alimento passa?

V V V

Os estudantes envolvidos na atividade passaram a compreender ainda mais os temas trabalhados, uma vez que foram utilizados na aplicação do conteúdo modelos representacionais (Figura 2). Sendo assim, Silva [15] e Soares [16] defendem que o modelo concebe ao aluno como o participante ativo no processo de aprendizagem, designando ao professor à responsabilidade de proporcionar situações que estimulem e facilitem o processo ensino aprendizagem. 

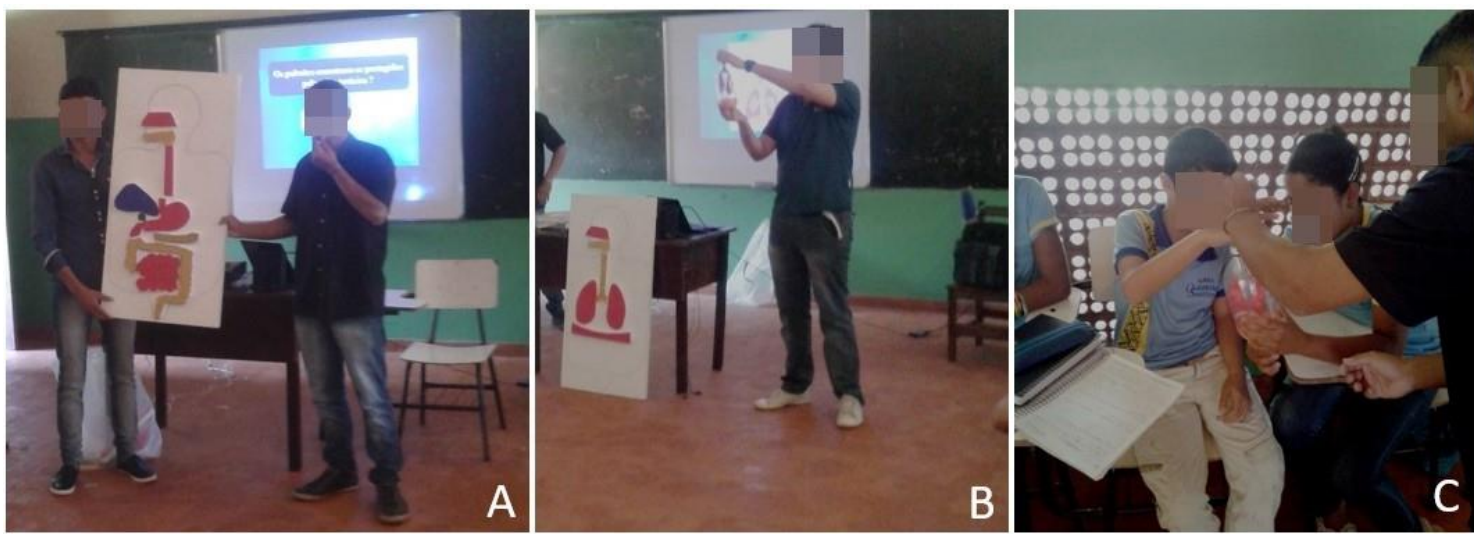

Figura 2: Modelagem do sistema digestório, A; Modelagem do sistema respiratório, B e C.

A partir da análise das reações, atitudes e o diálogos dos alunos durante o desenvolvimento da prática, percebeu-se que modelos são positivos para o ensino de ciências, visto que o envolvimento dos alunos na dinâmica da montagem até o resultado final tem por promover um aprendizado significativo em relação aos conceitos discutidos em sala de aula. Durante o processo de elaboração muitas dúvidas foram questionadas e esclarecidas, alguns conceitos prévios foram substituídos por novos conceitos ainda não discutidos pelo professor, pois estes se encontravam de maneira errônea dentro das falas restritas dos alunos. Com isso, para Ausubel [17] o ensino se torna significativo quando o aluno relaciona o seu conhecimento prévio com novos conceitos.

Em relação à importância que os discentes atribuem as aulas com uso da ferramenta modelagem, cerca de $96 \%$ consideraram esta atividade importante para o ensino de ciências, como evidenciado no gráfico (Figura 3), e por complemento pode ser observado nos relatos dos discentes identificados pelas letras A, B, C e D.

"Eu não conhecia a modelagem, é muito legal, pois eu participei mais da aula, é porque eu não gosto de ciências, risos". (A)

Os alunos ressaltaram a importância das aulas de ciências com modelagem, como destacou o aluno B:

"É a primeira vez que eu tenho uma aula de ciências com modelagem, e ela ajuda muito pois para mim ficou mais fácil entender o assunto". (B)

Foi notado que o uso de modelos contribuiu para que os alunos adquirissem novos conhecimentos, pois quando foram questionados em relação no que aprenderam os mesmos destacaram a importância de ter uma boa digestão e prática de exercícios físicos como pode ser observado abaixo:

"Aprendi, que temos que praticar exercícios físicos para que o nosso sistema respiratório funcione bem”. (C)

"Eu pensava que a digestão só começava no estômago, mas agora eu aprendi que a digestão começa na boca e é importante saber disso". (D) 


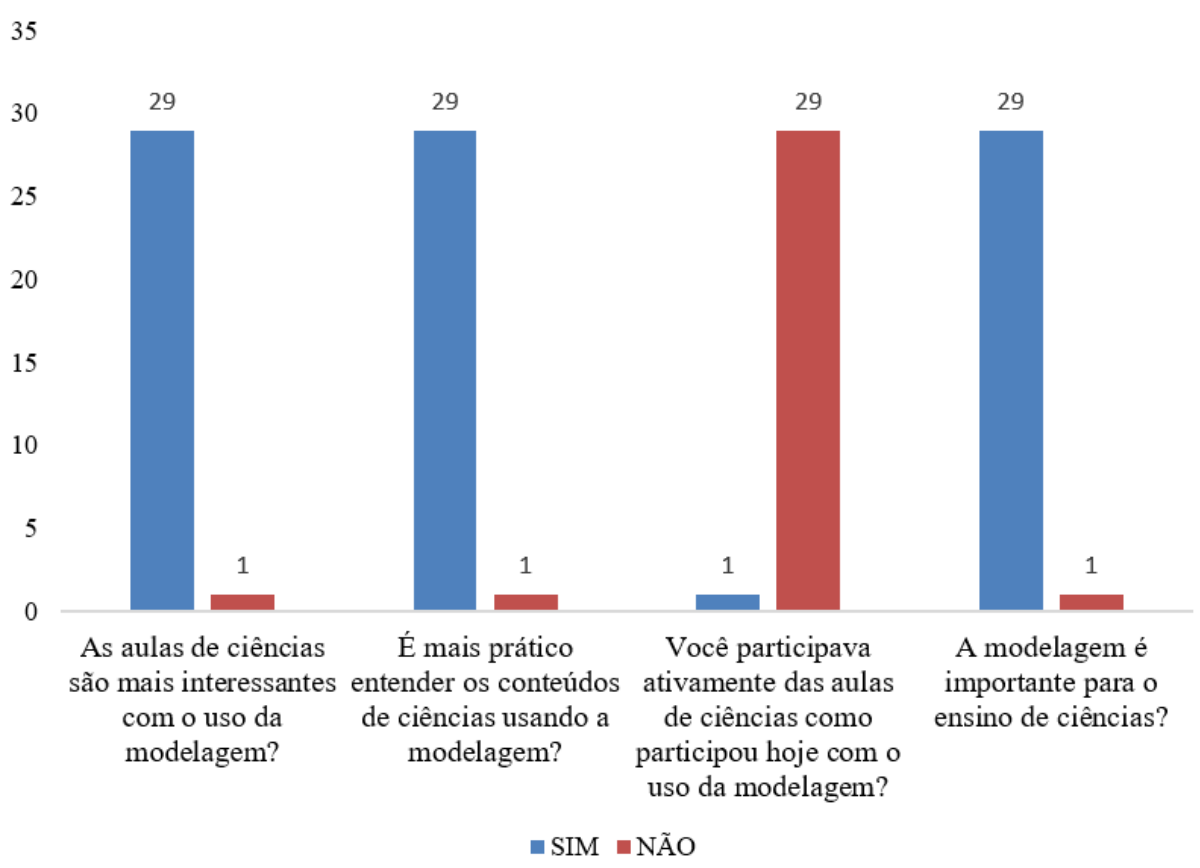

Figura 3: Questionário aplicado após a execução do trabalho, com objetivo de avaliar os alunos de acordo com a sua aprendizagem obtida no decorrer das atividades

Os alunos avaliaram o trabalho por meio de conceitos que iam deste excelente a ruim, e os resultados foram satisfatórios, pois $60 \%$ da turma disseram que a aula foi excelente, cerca de 23,4\% ótima e 16,6\% bom. Comparando com os resultados obtidos por Mendonça; Santos [9], percebe-se que estes se aproximam dos mesmos obtidos neste trabalho, visto que essa metodologia de ensino se encaixa como nova tendência pedagógica de ensinar ciências no ensino fundamental. Duso [4] descreve que os usos de modelos possibilitem a obtenção de conceitos aproximados da realidade, como fenômenos de respiração dos sistemas humanos, e também ressalta o constante entusiasmo e curiosidade dos alunos durante a execução das atividades.

\section{CONCLUSÃo}

A aprendizagem por meio de atividades de modelagem proporciona aulas na qual o aluno torne-se mais participativo, mostrando um maior interesse em aprender. $\mathrm{O}$ uso da modelagem representacional é uma forma de proporcionar aos estudantes um potencial que possa facilitar a aprendizagem dos conteúdos, a modelagem é vista como um processo de construção, reformulação e validação de modelos, as evidências mostraram que o conteúdo trabalhado se deu de forma mais significativa, visto que o estudante possa desenvolver um conceito mais coerente e crítico da ciência.

O experimento de aula com auxílio da modelagem representacional se fez válido no ensino de ciências, uma vez que, foi alcançado o objetivo esperado de ampliar o conhecimento dos discentes acerca do sistema digestório e respiratório. No entanto, a produção de modelos representacionais requer tempo e dedicação dos profissionais responsáveis por levar essa nova metodologia de ensino para a sala de aula. A Universidade do Estado do Pará, assim como outras universidades possui o papel de formar docentes capacitados para utilizar ferramentas pedagógicas no intento de diminuir os entraves enfrentados em sala de aula.

Com isso, é notório que a aplicação deste projeto pode proporcionar a todos os estudantes presentes como o uso de uma metodologia de ensino pode mudar completamente o nível de aprendizagem dos assuntos a serem introduzidos em sala de aula. Constatando que o processo de formação de professores deve se primar não só pelo conhecimento teórico, mas também pelos métodos utilizados para tornar o conhecimento acessível para a compreensão. 


\section{REFERÊNCIAS BIBLIOGRÁFICAS}

1. Ferreira PFM. Modelagem e suas contribuições para o ensino de ciências: uma análise no estudo de equilíbrio químico [Dissertação de Mestrado], UFMG, Belo Horizante, 2006. 165p

2. Barab SA, Hay KE, Barnett M, Keating T. Virtual solar system Project: building understanding trough model building. Journal of Research in Science Teaching 2000; 37(1):719-756.

3. Greca IM, Santos FMT. Dificuldades da generalização das estratégias de modelação em ciências: o caso da física e da química. Investigações em Ensino de Ciências 2005; 10(1):31-46.

4. Duso L. Encontro Nacional de Didática e Práticas de Ensino. UNICAMP. Campinas: 2012. 432p.

5. Paz AM, Abegg I, Alves Filho JP, Oliveira VLB. Modelos e modelizações no ensino: Um estudo da cadeia alimentar. Revista Ensaio 2006; 8(2): 133-146.

6. Duso L, Clement L, Pereira PB, Filho JPAF. Modelização: uma possibilidade didática no ensino de biologia. Revista ensaio 2013; 15(2):29-44.

7. Pietrocola M. Construção e Realidade: o realismo científico de Mário Bunge e o ensino de ciências através de modelos. Investigações em ensino de Ciências 1999; 4(3): 213-227.

8. Moreira MA. Mapas conceituais e aprendizagem significativa. Editora, Centouro. 2010. 14p.

9. Mendonça CO, Santos MWO. Modelos didáticos para o ensino de ciências e biologia: Aparelho Reprodutor Feminino da Fecundação a nidação. In: V Colóquio internacional. São Cristovão. 2011.

10. Souza DC, Andrade PGL, Nascimento Júnior AF. Produção de Material Didático-Pedagógico Alternativo para o Ensino do Conceito Pirâmide Ecológica: Um Subsídio a Educação Cientifica e Ambiental. In: IV Fórum Ambiental da Alta Paulista. São Paulo. 2008.

11. Krasilchik M. Prática de Ensino de Biologia. São Paulo: Edusp, 2008. 197p.

12. Treagust DF, Chittleborough G. Chemistry: A Matter of Understanding Representations. In: Brophy J. (Ed.) Subject-Specific Instructional Methods and Activities. Oxford: Elsevier Science. 2001. 239267p.

13. Brasil. Secretaria de Educação Fundamental. Parâmetros Curriculares Nacionais: Ciências Naturais. Secretaria de Educação Fundamental. Brasília 1998.

14. Libâneo JC. Didática: $28^{a}$ reimpressão; São Paulo: Cortez, 2008.

15. Silva CMR. O Modelo Didático do Gênero Comentário Jornalístico Radiofônico: Uma Necessária Etapa para a Intervenção Didática [Dissertação de Mestrado] PUC-SP, São Paulo, 2009.

16. Soares MC. Uma Proposta de Trabalho Interdisciplinar Empregando os Temas Geradores Alimentação e Obesidade [Dissertação de Mestrado] UFSC, Rio Grande do Sul, 2010.

17. Ausubel D. Aquisição e retenção de conhecimentos: Uma perspectiva cognitiva.Lisboa: Editora Plátano, 2003. 